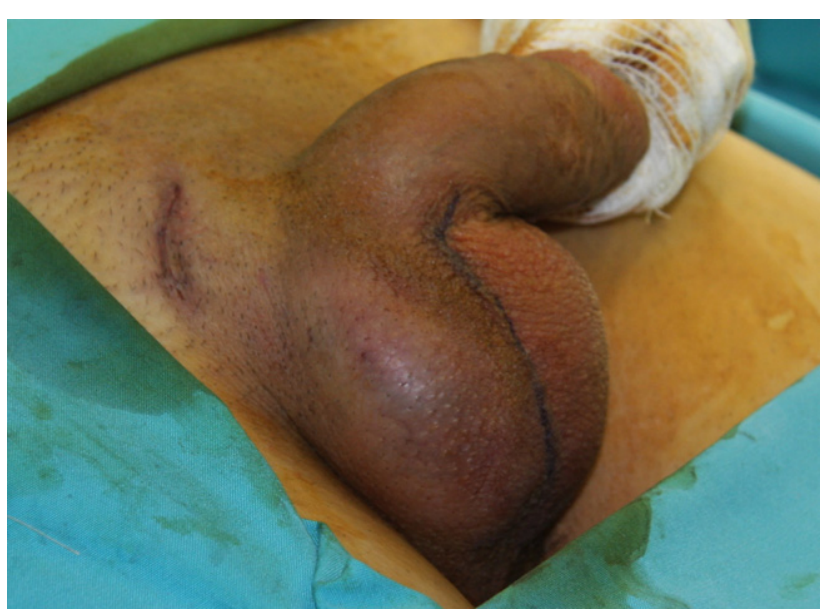

Figura 2 - Resultado final. Correcto emplazamiento así como adecuado tamaño y simetría.

mediante eversión digital de este y exposición a través de la incisión. Se colocó una prótesis de $4,5 \times 3 \times 2 \mathrm{~cm}$. Se suturó la incisión con sutura reabsorbible $4 / 0$ para el subcutáneo y puntos sueltos de nylon 5/0 para la piel. Fijando la prótesis con esta técnica, aseguramos un correcto emplazamiento y prevenimos una posible elevación a la par que mejoramos el resultado final (fig. 2).

La utilización de esta técnica, asociando la incisión supraescrotal y la utilización del catéter de Foley para una correcta estimación del tamaño, nos permite asegurar un correcto emplazamiento así como un adecuado tamaño y simetría de la prótesis. El contacto entre la cicatriz y la prótesis puede resultar en contaminación de la prótesis; este contacto suele ocurrir ya sea con una incisión inguinal o escrotal. Los resultados estéticos de estos abordajes tampoco suelen ser óptimos. Sin embargo, el abordaje supraescrotal tiene la ventaja de quedar oculto por el vello púbico así como de dejar el escroto libre de cicatrices. La fijación de la prótesis al escroto previene su elevación y asegura un correcto emplazamiento. El uso del catéter de Foley proporciona un sencillo y práctico sistema de medida que asegura la correcta elección de tamaño de la prótesis, repercutiendo todo ello en una mayor satisfacción del paciente.

B I B L I O G R A F Í A

1. Winkler H, Kleinmann N, Raviv G, Chertin B, Ramon J, Mor Y. Testicular prosthesis insertion following testicular loss or atrophy during early childhood-technical aspects and evaluation of patient satisfaction. J Pediatr Urol. 2007;3:461-5.

2. Adshead J, Khoubehi B, Wood J, Rustin J. Testicular implants and patient satisfaction: A quiestionnaire-based study of men after orchidectomy for testicular cancer. BJU Int. 2001;88: 559-62.

C. Casale*, J. Buendía-Pérez, J. Botellé-Del Hierro y

B. Hontanilla-Calatayud

Departamento de Cirugía Plástica, Clínica Universidad de Navarra, Pamplona, España

*Autor para correspondencia.

Correo electrónico: drcasale@hotmail.es (C. Casale).

\title{
Tumor fibroso solitario renal (reporte de caso)
}

\section{Solitary fibrous tumor of the kidney (a case report)}

\section{Sr. Director:}

Los tumores fibrosos solitarios (TFS) son tumores mesenquimales de probable tipo (mio)fibroblástico que muestran un característico patrón vascular ramificado hemangiopericitoide que usualmente se desarrollan en la pleura.

Hasta un $30 \%$ de los casos han sido reportados en partes blandas y órganos parenquimales. Pocos son los casos descritos en el riñón ${ }^{1-8}$.

Se trata de una paciente de 39 años, con disuria y polaquiuria, a la que se le diagnosticó infección del tracto urinario. La TAC reportó una lesión sólida, hipodensa, captadora de contraste de forma heterogénea, de $2,3 \mathrm{~cm}$ de diámetro mayor y que condicionaba infiltración del sistema colector adyacente. Se realizó nefrectomía radical izquierda y linfadenectomia paraórtica.

A nivel de la pelvis renal se identificó una neoformación nodular, sólida, pardo clara, de bordes expansivos, de $2,5 \mathrm{~cm}$ de diámetro mayor. El resto del riñón no tenía alteraciones significativas.

Microscópicamente (fig. 1), el tumor era fusocelular, de celularidad moderada, con bandas hialinas de colágeno, atipia nuclear ausente e índice mitótico bajo, el parénquima renal estaba focalmente comprometido. El perfil inmunohistoquímico fue CD34(+) (fig. 2), Bcl-2(+), CD99(+), S-100(-), desmina(-), actina(-), HMB-45(-), CD117(-) e índice proliferativo (Ki67) bajo: del 2-3\%.

Los TFS son neoplasias mesenquimales reportadas en partes blandas y diversos órganos. Son neoplasias primitivas mesen- 


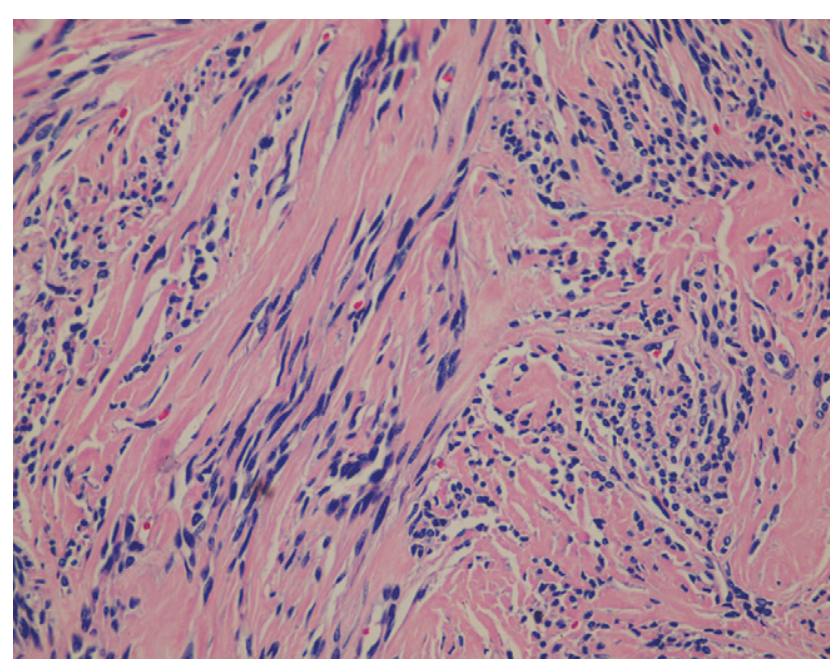

Figura 1 - Neoplasia de patrón fusocelular, con densas bandas hialinas de colágeno.

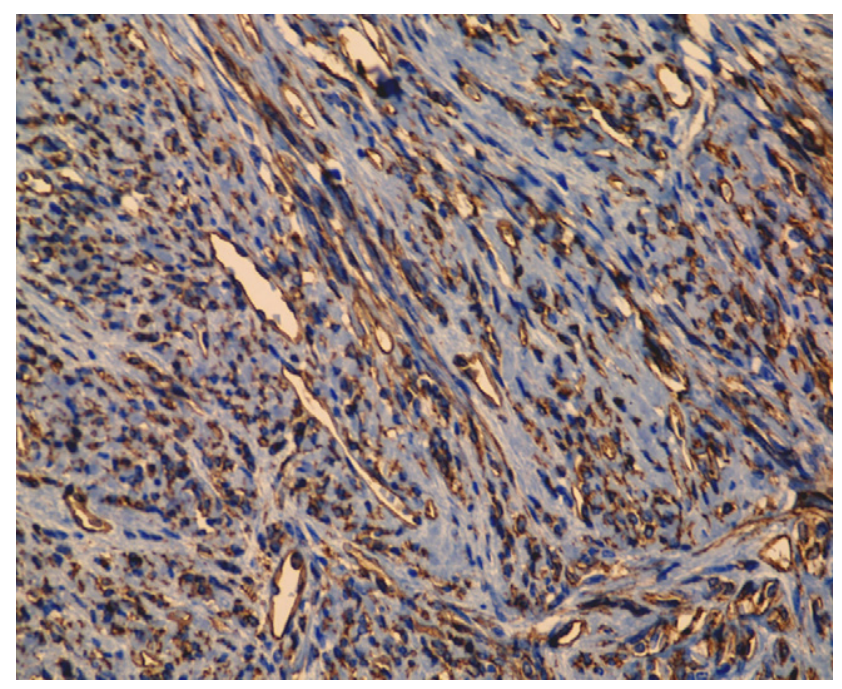

Figura 2 - Positividad difusa para la inmunotinción con CD34.

quimales (mio)fibroblásticas con características de diferenciación múltiple ${ }^{9}$. A nivel renal, su sitio de origen ha sido discutido y se han planteado orígenes como la cápsula, el tejido conectivo intersticial y/o peripélvico o el parénquima renal ${ }^{3}$.

Clínica e imagenológicamente son confundidos con carcinomas o sarcomas de células renales, así como a causa de la presencia de hematuria indolora ${ }^{2}$. Pueden ser unilaterales o bilaterales $^{8}$. Macroscópicamente son bien circunscritos o pseudoencapsulados, lobulados, firmes o elásticos, con una superficie de corte blanco grisáceo; pueden contener áreas quísticas hemorrágicas o de necrosis ${ }^{3}$. Su tamaño es variable.

El diagnóstico definitivo es microscópico. Muestran con predominio un patrón fusocelular, y la disposición de las células varía de área en área. En algunas zonas, las células pueden formar pequeños fascículos mal definidos, mientras que en otras muestran una disposición desordenada. Otra característica es la notoria hialinización tipo «queloidal»; aquí las células usualmente se disponen aisladas o en pequeños grupos paralelos y cercanos a los haces de colágeno denso. Los bordes celulares están pobremente definidos y el citoplasma es escaso. Puede haber cambios mixoides focales y calcificación distrófica. El patrón vascular es característicamente pericítico (hemangiopericitoide) con una variable hialización perivascular ${ }^{1-3,9}$.

Su perfil inmunohistoquímico es positividad para CD34 (el $80-95 \%$ de los casos). Pueden también expresar CD99 (70\%), Bcl-2 (50\%), EMA (30\%) y actina (20\%). Ocasionalmente pueden presentar positividad focal para proteína S-100, citoqueratinas y/o desmina, pero por lo general son negativos para estas últimas.

Nuestro caso mostró positividad marcada difusa para CD34, CD99 y Bcl-2; siendo negativo para actina y desmina. La positividad para CD34 puede no ser específica, pero asociada a la negatividad para otros marcadores y a los hallazgos microscópicos permiten distinguirlo.

No se han identificado aún típicas alteraciones (cito)genéticas. Se sugiere que existe un amplio rango de cambios genéticos en los TFS, no habiendo una aberración consistente o específica que pueda ser útil en el diagnóstico de esta enfermedad ${ }^{10}$.

El comportamiento de los TFS es impredecible ${ }^{5,9}$, pudiendo comportarse de forma agresiva caracterizada por recurrencia local y metástasis a distancia. Este comportamiento biológico no se correlaciona con las características histomorfológicas atípicas ${ }^{9}$. Los criterios típicamente descritos para malignidad son patrón sarcomatoide, celularidad aumentada, pleomorfismo celular, actividad mitótica aumentada ( $>4$ mitosis en 10 campos de alto poder) y necrosis.

El diagnóstico diferencial del TFS es amplio, incluyendo lesiones benignas fusocelulares que pueden tener patrón hemangiopericitoide, como fibroma, hemangiopericitoma, tumor miofibroblástico inflamatorio, angiolipoma, leiomioma, schwannoma, la mayoría de los sarcomas (leiomiosarcoma, sarcoma sinovial, fibrosarcoma, tumor maligno de la vaina del nervio periférico, sarcoma sinovial y tumor del estroma gastrointestinal maligno) y carcinoma de células renales sarcomatoide. Por tanto, los estudios de inmunohistoquímica son imprescindibles para el diagnóstico definitivo de esta neoplasia.

El tratamiento de esta neoplasia es quirúrgico y se deben tratar de resecar todos los tumores con márgenes quirúrgicos adecuados. La resecabilidad es el factor determinante más importante de recurrencia. Es recomendable hacer un cuidadoso seguimiento clínico en todos los casos. El rol de la terapia adyuvante aún no se ha definido.

Nuestra paciente tuvo una evolución buena sin evidencias de recurrencia ya a un año de su tratamiento quirúrgico.

B I B L I O G R A F Í A

1. Chan JKC. Solitary fibrous tumor-everywhere, and a diagnosis in vogue. Histopathology. 1997;31:568-76.

2. Hasegawa T. Solitary fibrous tumor. En WHO pathology and genetics of tumours of the urinary system and male genital organs. Lyon. 2004;75.

3. Kaoutar Z, Chbani L, Znati K, El Fatemi H, Harmouch T, Zaki Z, et al. Solitary fibrous tumor of the kidney: A case report and review of the literature. Rev Uro. 2007;9:36-40. 
4. Wang J, Arber D, Znati K, El Fatemi H, Harmouch T, Zaki Z, et al. Large solitary fibrous tumor of the kidney. Am J Surg Pathol. 2001;25:1194-9.

5. Xambre L, Lages R, Cerqueira M, Silva V, Prisco R, Santos R, et al. Tumor fibroso solitario. Dos casos adicionales con implicancias urológicas. Actas Urol Esp. 2003;27: 832-8.

6. Magro G, Cavallaro V, Torrisi A, Lopes M, Dell'Albani M, Lanzafame S. Intrarenal solitary fibrous tumor of the kidney report of a case with emphasis on the differential diagnosis in the wide spectrum of monomorphous spindle cell tumors of the kidney. Pathol Res Pract. 2002;198:37-43.

7. Yasaki T, Satoh S, Iizumi T, Umeda T, Yamaguchi Y. Solitary fibrous tumor of renal pelvis. Int J Urol. 2001;8:504-8.

8. Llarena R, Eizaguirre B, Zarzai B, Lecumberri Castanos D, et al. Bilateral renal solitary fibrous tumor. Arch Esp Urol. 2003;56: $835-40$.
9. Graadt van Roggen JF, Hogendoorn PCW. Solitary fibrous tumour: The emerging clinicopathologic spectrum of an entity and its differential diagnosis. Curr Diagn Pathol. 2004;10:229-35.

10. Torabi A, Lele SM. Lack of a common or characteristic cytogenetic anomaly in solitary fibrous tumor. Cancer Genet Cytogenet. 2008;181:60-4.

L. Taxa ${ }^{a}$, L. Huanca ${ }^{a, *}$, L. Meza ${ }^{b}$ y M. Pow Sang ${ }^{b}$

${ }^{a}$ Departamento de Patología, Instituto Nacional

de Enfermedades Neoplásicas, Lima, Perú

${ }^{\mathrm{b}}$ Departamento de Cirugía Urológica, Instituto Nacional

de Enfermedades Neoplásicas, Lima, Perú

*Autor para correspondencia.

Correo electrónico: Lulita1411@gmail.com (L. Huanca).

\section{Extrusión de prótesis testicular: presentación de un caso y revisión de la literatura médica}

\section{Extrusion of a testicular prosthesis: Presentation of a clinical note and review of the literature}

\section{Sr. Director:}

Presentamos el caso de un paciente varón de 23 años de edad que acudió al Servicio de Urgencias de nuestro hospital por presentar una tumoración en el hemiescroto izquierdo, acompañada de intenso dolor y de dos días de evolución. Entre sus antecedentes personales refería haber sufrido un traumatismo testicular izquierdo a los 9 años de edad, siendo intervenido 2 meses después de este.

Dos días antes de acudir a nuestro hospital consultó con su médico de atención primaria por presentar una tumoración en el hemiescroto izquierdo de aproximadamente $0,5 \mathrm{~cm}$ de diámetro y que se acompañaba de signos inflamatorios cutáneos. Fue diagnosticado de quiste sebáceo escrotal complicado y tratado con antibióticos y antiinflamatorios. Veinticuatro horas después de iniciar el tratamiento médico observó la presencia de una escara negruzca en el centro de la tumoración que aumentó de tamaño en el plazo de varias horas y que, al desprenderse, dejó visible el material protésico.

En la exploración física, el paciente se encontraba apirético y normotenso. Se apreció la extrusión parcial de una prótesis testicular en la región superoexterna del hemiescroto izquierdo, el cual no presentaba signos inflamatorios ni hemorragia (fig. 1). Sorprendentemente, el paciente desconocía que en la intervención quirúrgica realizada en la infancia le practicaron orquiectomía izquierda e implante de prótesis testicular de silicona. El resto de la exploración era normal.

Bajo anestesia local se procedió a la extracción completa de la prótesis testicular del escroto, al lavado de la cavidad con solución de clorhexidina al 0,1\%, al refrescamiento y a la sutura de los bordes cutáneos. Durante la intervención se apreció la presencia de una pseudocápsula fibrosa y de superficie lisa alrededor del lugar que ocupaba la prótesis. Se revisó la herida a los 7 días, encontrándose en perfectas condiciones. A los 2 meses el paciente se encontraba asintomático. El paciente rechazó la colocación de una nueva prótesis.

La ausencia de un testículo puede suponer para el paciente una experiencia traumática desde el punto de vista psicológico, con sensación de inferioridad, alteraciones en la función sexual y efectos sobre el desarrollo psicosocial. Es más probable que esto ocurra en pacientes que han perdido un testículo que en aquellos que han nacido sin él.

La relativa facilidad de colocación de la prótesis testicular, su similitud con un testículo normal y el bajo grado de complicaciones permiten reconstruir un escroto aparentemente normal en aquellos pacientes que han presentado la pérdida de un testículo o han nacido sin él ${ }^{1}$.

\section{Indicaciones para la implantación de prótesis testicular}

Las causas más frecuentes para la indicación de la colocación de una prótesis son la agenesia o la atrofia testicular. En pacientes con criptorquidia se puede encontrar atrofia o agenesia testicular hasta en un $10 \%$ de los casos. Las causas de indicación de orquiectomía y la colocación de una prótesis testicular según una encuesta realizada a los urólogos de la sección occidental de la AUA en $1986^{2}$ son el testículo atrófico o no descendido (35\%), la torsión testicular (23\%), el tumor 